\title{
Regulatory mechanisms of apoptosis in regularly dividing cells
}

\author{
This article was published in the following Dove Press journal: \\ Cell Health and Cytoskeleton \\ 13 August 2010 \\ Number of times this article has been viewed
}

\section{Ribal S Darwish \\ Department of Anesthesiology, Division of Critical Care Medicine, University of Maryland Medical Center, Baltimore, Maryland, USA}

Correspondence: Ribal S Darwish Department of Anesthesiology, Division of Critical Care Medicine, University of Maryland Medical Center, 22 S Greene St, Baltimore, Maryland 2I 20I-1595, USA

$\mathrm{Tel}+\mathrm{I}(4 \mathrm{IO}) 328-6120$

Fax +I (4I0) 328-0544

Email rdarwish@anes.umm.edu

\begin{abstract}
The balance between cell survival and death is essential for normal development and homeostasis of organisms. Apoptosis is a distinct type of cell death with ultrastructural features that are consistent with an active, inherently controlled process. Abnormalities and dysregulation of apoptosis contribute to the pathophysiology of multiple disease processes. Apoptosis is strictly regulated by several positive and negative feedback mechanisms that regulate cell death and determine the final outcome after cell exposure to apoptotic stimuli. Mitochondria and caspases are central components of the regulatory mechanisms of apoptosis. Recently, noncaspase pathways of apoptosis have been explored through the studies of apoptosis-inducing factor and endonuclease G. Multiple difficulties in the apoptosis research relate to apoptosis detection and imaging. This article reviews current understanding of the regulatory mechanisms of apoptosis.

Keywords: caspases, apoptosis-inducing factor, apoptosis inhibitory proteins, cytochrome c, mitochondria
\end{abstract}

\section{Introduction}

Apoptosis is a distinct type of cell death with ultrastructural features that are consistent with an active, inherently controlled process, and it is a part of the necrobiosis, a process that is essential in maintaining tissue homeostasis. The concept that cells must be lost from the normal tissues to balance their mitotic activity was first proposed by the German anatomist Ludwig Graper, ${ }^{1}$ who proposed that chromolysis must exist in the cells that will be eliminated. Later, critical experiments by Kerr and Wyllie identified apoptosis as a distinct form of cell death. ${ }^{2,3}$ Apoptosis is of Greek origin, meaning "falling off or dropping off" in analogy to leaves falling off trees; it is highly regulated and an efficient form of programmed cell death. Abnormalities and dysregulation of apoptosis contribute to the pathophysiology of multiple disease processes. Uninhibited apoptosis exacerbates many conditions including acquired neurodegenerative disorders, such as Alzheimer and Huchington diseases, cardiac ischemia, stroke, and traumatic brain injury. Conversely, inadequate apoptosis leads to the development of autoimmune diseases and cancer. The underregulation of apoptosis is a key component in cancer and tumor-cell uninhibited proliferation, as well as tumor resistance to chemotherapy. There are complex pathologies where the upregulation and underregulation of apoptosis in different cell types are present at the same time.

Based on the morphological characteristics, two patterns of cell death have been well described: apoptosis and necrosis. Apoptosis is a form of cell death characterized by cell shrinkage, chromatin condensation, fragmentation of the nucleus and bubbling of the plasma membrane ${ }^{4}$ (known as "blebbing"), long-lasting maintenance of plasma 
membrane integrity, lack of inflammatory responses to the dying cell, with the formation of apoptotic bodies that are consumed by macrophages or neighboring cells. In contrast, necrosis begins with an impairment of the cell's ability to maintain homeostasis, leading to organelle swelling, most notably the mitochondria, with eventual cell lysis. This pattern of cell death leads to inflammatory response. A less characterized form of cell death is one in which cells that are deprived of exogenous energy sources catabolize part of their cytoplasm to generate ATP and other intermediate metabolites. This allows them to meet their essential energetic demand; a process called autophagic cell death ${ }^{5}$ is also an essential process in the removal of the damaged mitochondria. Another form of cell death is mitotic catastrophe, which is characterized by cell arrest during mitosis as opposed to the classical apoptosis that occurs during the interphase.$^{6}$ Recent data indicate that opposition between apoptosis and necrosis is less clear; necrosis can be prevented by bcl-2 family. In certain situations, apoptosis induction gives rise to more necrotic features when cytosolic ATP levels are low, so the changes in the mitochondrial permeability can lead to both necrosis and apoptosis. ${ }^{7,8}$

Apoptosis is strictly regulated by several positive and negative feedback mechanisms that regulate cell death and determine the final outcome after cell exposure to stressful stimuli. An intrinsic and extrinsic pathway of apoptosis had been proposed to reflect the more prominent contributions of the mitochondria to the apoptotic process in the intrinsic pathway as opposed to the extrinsic pathway, where apoptosis is significantly affected by cell receptors. It is important to recognize that the regulatory mechanisms of cell death and apoptosis are not uniform and varies depending on cell type, response to stressful stimuli, and age of the cell. Commonly, the induction of apoptosis is regarded as an event related to a specific apoptotic stimulus, but the apoptosis signaling pathway is functional in viable cells and kept downregulated in an inactive state. The apoptotic signaling pathways are genetically encoded and can be expressed or upregulated with proper stimuli.

\section{Extrinsic pathway of apoptosis}

The extrinsic pathway of apoptosis is initiated by the activation of specific cell surface receptors, specifically by the members of the tumor necrosis factor (TNF) super family. These receptors are type II transmembrane proteins. Their extracellular domain, when cleaved by proteinases, produces soluble cytokines (stalk of varying length) that connects the transmembrane domain to a core region and contains the hallmark structure of the TNF family. The primary receptors of the TNF super family contrib- uting to the extrinsic pathway of apoptosis are TNFRSF10A, B (TRAIL R1/DR4, TRAIL R2/DR5), TNFRSF 6 (Fas/Apo-1), TNFSF1 R1 (CD120), and TNFRSF25 (RAMP, LARD, WSL-1, DR3). These are activated by the binding of a specific corresponding ligand such as Apo2L/TRAIL (TNF-related apoptosis-inducing ligand), CD95 ligand (Fas ligand), TNF- $\alpha$, and DR3 ligand.

Fas receptor is a prototype member of the TNF/nerve growth factor receptor superfamily of death receptors. After Fas ligation, Fas receptor associates with Fas-associated protein death domain (FADD) and initiator cysteinedependent aspartate-specific proteases (procaspases), such as procaspase-8, procaspase-10, or procaspase-2, to form a "death inducing signaling complex" (DISC). Caspase- 8 may process and activate effecter caspases such as caspase-3, which activates deoxyribonuclease (DNAse) or caspase-8 cleaves BID/tBID (BH3-interacting death domain) to cause change in mitochondrial permeability and release of cytochrome $\mathrm{c}$ and Smac/Diablo. The best characterized enzyme responsible for DNA fragmentation is the caspase-3-activated DNAse CAD, which exists in the cytosol as inactive ICAD/ CAD complex. Activated caspase- 3 causes the release of CAD from this complex, which then translocates from the cytosol to the nucleus. ${ }^{9,10}$ NUC70 along with DNase 1 have been reported as effective DNase during apoptosis. ${ }^{11}$ DNase 1 - deficient cells show prolonged survival and delayed apoptosis following pharmacological stimuli. ${ }^{12}$ DISC formation is modulated by several regulatory mechanisms, including c-FLICE inhibitory protein (c-FLIP), a cellular Fasassociated death domain-like interleukin-1-beta converting enzyme (FLICE) inhibitory proteins (c-FLIPs), which are endogenous caspase homologues that inhibit programmed cell death. The short form, c-FLIP(s), contains 2 deatheffector domains and is structurally related to the viral FLIP inhibitors of apoptosis, whereas the long form, c-FLIP (1), contains in addition a caspase-like domain in which the active-center cysteine residue is substituted by a tyrosine residue. c-FLIP(s) and c-FLIP (L) interact with the adaptor protein FADD and the protease FLICE, and potently inhibit apoptosis induced by all known human death receptors. ${ }^{13,14}$

TNF-related apoptosis-inducing ligand (TRAIL) is a ligand molecule, which induces apoptosis. It is a type II transmembrane protein and a member of the TNF ligand family. TNFSF10 binds to several members of TNF receptor superfamily including TNFRSF10A/TRAILR1, TNFRSF10B/ TRAILR2, TNFRSF10C/TRAILR3, TNFRSF10D/TRAILR4, and possibly also to TNFRSF11B/OPG. The activity of this protein may be modulated by binding to the decoy 
receptors, such as TNFRSF10C/TRAILR3, TNFRSF10D/ TRAILR4, and TNFRSF11B/OPG, that cannot induce apoptosis. TNF receptor-associated death domain (TRADD) contributes to the DISC formation and activates caspase-8. ${ }^{15,16}$ Overexpression of TRADD leads to 2 major TNF-induced responses, apoptosis through caspase- 8 activation and activation of NF-kB. Interestingly, TNF pathway preferentially induces apoptosis in transformed and tumor cells but does not appear to kill normal cells although it is expressed at a significant level in most normal tissues. TRADD-independent pathway triggers a cell-death program that requires the function of cysteine proteases such as ICE or CPP32/Yama, which was demonstrated by activation of DR4/DR5 with TRAIL. ${ }^{17}$

It has been shown that activation of the extrinsic pathway, through the binding of CD95L/FasL to CD95/Fas and TNF- $\alpha$ to TNFR-1, induces 2 distinct caspase- 8 activation pathways. In the first pathway, cells are able to overcome the need for mitochondrial amplification of the death signal in CD95mediated apoptosis by producing sufficient amounts of caspase- 8 at the DISC to directly cleave and activate effector caspases and induce cell death; this pathway can be inhibited by c-FLIP. ${ }^{18,19}$ Because in this pathway cells bypass mitochondrial involvement, expression of Bcl-2 or Bcl-XL has no inhibitory effect on their apoptotic program. Conversely, type II cells produce minimal amounts of active caspase- 8 at the DISC and require the mitochondrial amplification. This pathway is less sensitive to c-FLIP inhibition. The signal is probably amplified through the pro-apoptotic $\mathrm{BH} 3$ domain, which only contains the Bcl-2 family member, Bid. ${ }^{20,21}$ The cleavage of Bid by caspase- 8 results in its translocation to the mitochondria where it initiates the release of mitochondrial factors, which in turn augment cell death. Because type II cells rely on the apoptotic function of mitochondria, expression of $\mathrm{Bcl}-2 / \mathrm{Bcl}-\mathrm{XL}$ does provide protection from CD95-mediated apoptosis..$^{20}$ It has been suggested that differential expression of inhibitors of the death receptor-signaling cascade, such as c-FLIP or X-linked inhibitor of apoptosis protein (XIAP) could explain the difference between type I and type II cells. ${ }^{18}$ Smac/Diablo and IAP interaction primarily affects the intrinsic pathway of apoptosis. Both intrinsic and extrinsic pathways converge at the step of caspase-3 activation; high levels of XIAP are able to inhibit activated caspase- 3 but not caspase- $8 .^{22}$ The alternative pathway for apoptosis is through activation of BID. tBID can release Smac/Diablo from the mitochondria to block the IAPs and thus releasing the IAPs inhibitory effect on caspase-3 (Figure 1).

In the extrinsic pathway of apoptosis, an alternative form of signal transduction is initiated by the withdrawal of ligands from specific receptors referred to as dependence receptors. Dependence receptors have been shown to promote programmed cell death in the absence of their appropriate ligand. ${ }^{23}$ Well-studied examples of dependence receptors include the neurotrophin receptor (p75NTR), ${ }^{24-26}$ the netrin receptors deleted in colorectal cancer, ${ }^{27-29}$ uncoordinated-5 homolog proteins, ${ }^{30}$ rearranged during transfection, ${ }^{31}$ a receptor for glial-derived neurotrophic factor, and integrins, which mediate cell anchorage to the underlying extracellular matrix substrate and regulates cell morphology. ${ }^{33,34}$ Unligated integrins initiate a caspase-8-dependent pathway. ${ }^{31,34}$

\section{Intrinsic pathway of apoptosis}

During cell apoptosis, cytochrome c along with other proteins (Smac/Diablo, Omi/HtrA2, apoptosis-inducing factor [AIF], endonuclease $\mathrm{G}$ ) are released from the mitochondrial membrane into the cytosol in response to specific apoptotic stimuli via multiple mechanisms including Bcl-2 familyregulated mechanisms. The Bcl-2 family proteins are critical cell regulators of apoptosis. Homologous domains $(\mathrm{BH})$ within individual proteins of the Bcl-2 family are necessary for interactions with other family members and for activity. The mammalian Bcl-2 family members are either proapoptic multidomain members (BAX, BAK, BOK/MTD) or BH3specific (BID, BAD, BIK/NBK, BLK, HRK, BIM/BOD/ BNIP3, NIX, NOXA). The antiapoptotic members exhibit the homology to all segments from BH1 to BH4 (BCL-2, BCL-xl, BCL-W, MCL-1, A1-BFL-1, BOO/DIVA, NR-13) and are antiapoptotic in function. It is the balance between these factors that influences cytochrome c release. ${ }^{19,35} \mathrm{Mul}-$ tiple hypotheses have been proposed to explain the proapoptotic mechanisms of the Bcl-2 family on the mitochondria, including nonspecific rupture of the outer mitochondrial membrane that increases the outer membrane permeability following an apoptotic stimulus, ${ }^{36,37}$ matrix swelling and outer mitochondrial membrane rupture in response to metabolic changes, ${ }^{38,39}$ and formation of hybrid channel by Bax and the voltage-dependent anion channel (VDAC). This was confirmed by electrophysiological studies on VDAC, and Bax together these proteins can form a hybrid channel with a larger pore size than either VDAC or Bax alone. ${ }^{21}$ Another possible mechanism is the formation of specific outer mitochondrial membrane channels by proapoptotic Bcl-2 protein. ${ }^{40}$

Other proteins like p53 also regulate members of the bcl-2 family like Bax. Significant research was carried out on the regulatory function of BID; cleavage of BID with the formation of truncated BID/tBID results in mitochon- 


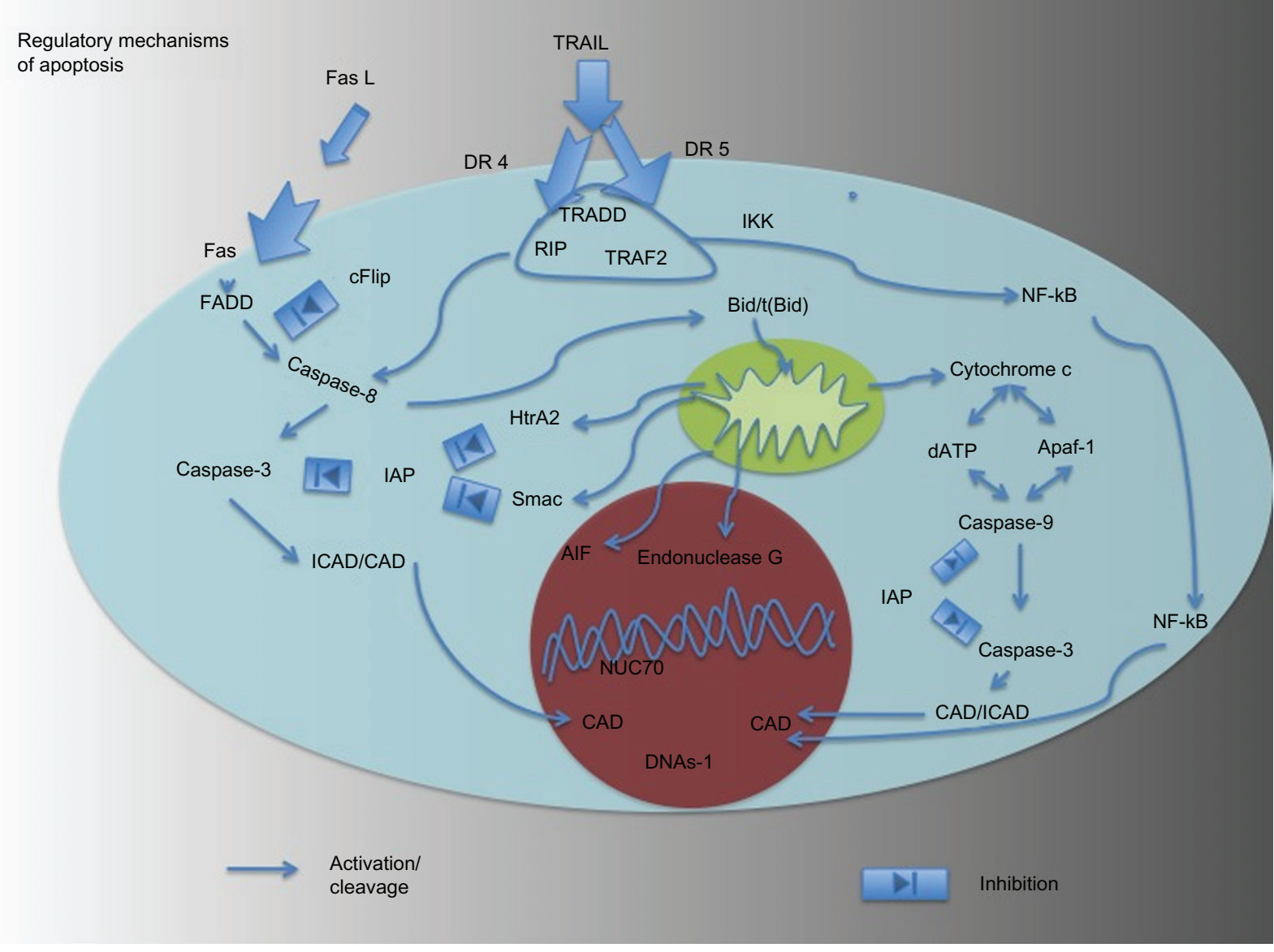

Figure I A diagram showing the basic regulatory mechanisms of apoptosis.

Abbreviations: FADD, Fas-associated protein death domain; TNF, tumor necrosis factor; Apaf-I, apoptotic protease activating factor-I; DISC, death inducing signaling complex; Smac, second mitochondria-derived activator of caspases; c-FLICE, cellular Fas-associated death domain-like interleukin-I-beta converting enzyme; c-FLIPs, FLICE inhibitory proteins; $\mathrm{BID}, \mathrm{BH}$-interacting death domain; $\mathrm{CAD}$, caspase-activated deoxyribonuclease.

drial membrane permeabilization with the resultant release of apoptotic mitochondrial proteins. Depletion of BID by immunoprecipitation from the cytoplasm of activated cells prevents cytochrome c release, which indicates that Bid is the first effecter molecule downstream of caspase- 8 that had such a capability. ${ }^{41}$ BCL-xl prevented tBID-induced depolarization. ${ }^{42,43} \mathrm{BIM}$ is another $\mathrm{BH} 3$ protein; recombinant BIM alone was found as efficient as tBID in releasing cytochrome $\mathrm{c}$ and endonuclease $\mathrm{G}$ when incubated with mitochondria in vitro. Another important regulatory player is the trophins. For example, neurotrophins activate and ligate Trk receptors that coordinate neuronal survival pathway PI (3) $\mathrm{K}$-AKt pathway; activation of AKt induces phosphorylation of $\mathrm{BAD}$, promotes its interaction with chaperone proteins, and inhibits BAD proapoptotic activity. ${ }^{44}$

Cytochrome $\mathrm{c}$ interacts with apoptotic protease activating factor-1 (Apaf-1). One of the major regulatory mechanisms by the $\mathrm{BH}-4$ domain of $\mathrm{Bcl}-2$ and $\mathrm{Bcl}-\mathrm{xl}$ is its ability to bind to the
C terminal part of Apaf-1 to cause an inhibition of association between Caspase-9 and Apaf-1. ${ }^{45-47}$ The Cytochrome c/Apaf-1 complex increases Apaf-1 affinity for dATP. The binding of dATP to the cytochrome/Apaf complex initiates its oligomerization to form the apoptosome, and the CARD domain of the Apaf-1 becomes exposed to multiple procaspase- 9 molecules leading to its activation and then cleaves the inactive procaspase-9 to generate activated caspase-9. Using purified recombinant Apaf-1 and procaspase-9 activation, Wang proposed 3-step model: (1) dATP/ATP binds to Apaf-1, (2) cytochrome $\mathrm{c}$ binds to Apaf-1 with multimerization of the cytochrome c Apaf-1 complex, and (3) procaspase-9 binds to the multimeric complex. ${ }^{48}$ This activated enzyme then initiates the apoptotic cascade, at the end of which is the effector caspase. Caspase-3 has many cellular targets that, when cleaved or altered, give the cell the characteristics of apoptosis. Once activated, a family of specific inhibitory proteins further regulates caspase function. IAPs, first studied in baculoviruses, 
were shown to be involved in suppressing the host-cell death response to viral infections. The antiapoptotic activity of IAPs has been attributed to the baculovirus IAP repeat (BIR) domain. To date, multiple IAPs are identified in humans, which include NAIP, c-IAP1/HIAP-2, cIAP2/HIAP-1, XIAP/hIlp, survivin, and BRUCE. ${ }^{49,50}$ Overexpression of XIAP, c-IAP1, c-IAP2, NAIP, or survivin has been shown to suppress apoptosis induced by a variety of stimuli and growth factor withdrawal. XIAP is the most potent inhibitor of apoptosis; its caspase inhibitory activity was first reported by Deveraux et al. ${ }^{51}$ NAIP gene was first identified in humans because of its deletion in patients with spinal muscular dystrophy, and it may also be involved in responses to ischemia. It was shown that transient brain ischemia elevates the levels of NAIP in rat neurons that are resistant to ischemia and reperfusion, ${ }^{52}$ but transfection experiments delayed and did not prevent induced apoptosis. In human cancers, survivin is expressed in high proportions but not in the differentiated adult tissue; interestingly reduction in survivin expression causes apoptosis and sensitization of tumor cells to cancer treatment. Several human IAPs were reported to directly block caspases-3. In the intrinsic pathway of caspase activation, XIAP, c-IAP1, and cIAP 2 bind directly to procaspase-9. Oxidative stress affects the cytochrome $\mathrm{c}$ activity; upon interaction of mitochondria-specific cardiolipin with cytochrome c, cytochrome c loses its tertiary structure and its peroxidase activity dramatically increases. Cardiolipininduced peroxidase activity of cytochrome $\mathrm{c}$ has been found to be important for selective cardiolipin oxidation in cells undergoing programmed death. ${ }^{53}$

Human Smac (second mitochondria-derived activator of caspases) and its mouse homolog Diablo (direct IAP binding protein with low $\mathrm{pI}$ ) is a mitochondrial protein that potentiates certain forms of apoptosis. It is released from the mitochondria into the cytosol and possibly by neutralizing one or more members of the IAP family of apoptosis inhibitory proteins. ${ }^{54}$ Smac/Diablo along with cytochrome c promotes apoptosis by activating caspases. The importance of mitochondrial efflux of Smac/Diablo, in response to a variety of proapoptotic agents, was demonstrated when microinjection of cytochrome $\mathrm{c}$ into neurons did not always induce apoptosis without pre-exposure to proapoptotic stimuli. Apoptosis is profoundly inhibited in Bcl-2-overexpressing cells. Bcl-2 regulates apoptosisassociated mitochondrial cytochrome c release, as well as Smac release, suggesting that both molecules may escape via the same route. However, mitochondrial cytochrome c release is largely caspase independent; a caspase inhibitor blocks the release of Smac/Diablo in response to the same stimuli. The releases of cytochrome $\mathrm{c}$ and Smac/Diablo from mitochondria occur through different mechanisms. Smac/Diablo release from mitochondria is a caspase-catalyzed event that occurs downstream of cytochrome $\mathrm{c}$ release. When cytochrome $\mathrm{c}$ is released and interacts with Apaf-1, it triggers caspase activation and apoptosome formation; AIPs will inhibit the activated caspases and stop the apopsome formation, ${ }^{55}$ and the inhibition could be permanent because many IAPs contain RING finger domain that targets the bounded caspases for proteasome degradation. ${ }^{56,57}$ This mechanism will prevent apoptosis when the release of cytochrome $\mathrm{c}$ does not reach the critical threshold. The role of Smac/Diablo has been reported in global ischemia reperfusion models, focal ischemia models but not in traumatic brain injury (TBI) models. Minocycline has been proposed as an agent that can decrease cytochrome $\mathrm{c}$ and Smac/Diablo leakage, as well as increase XIAP levels. ${ }^{58}$

The second antagonist of IAP along with Smac/Diablo is Omi/HtrA2, which is a mitochondrial serine protease that is released to antagonize the IAPs. They are both nuclear-encoded mitochondrial proteins; the cleavage of their mitochondrial-targeting sequence generates active Smac and Omi with new apoptogenic $\mathrm{N}$ termini, named the IAP binding motif; after their release, they bind to the BIR domain. Reports had shown selective IAP antagonism with Omi. By incubating different IAP proteins with Omi, Omi could cleave various AIPs including cIAP1, cIAP2, XIAP, DIAP1, livin $\alpha$, livin $\beta$; this activity was absent for survivin. An important implication for cancer research. The binding of Omi to IAPs produces catalytic proteolysis of IAPs, which is the key mechanism for Omi to irreversibly reduce IAP inhibition and promote cell death. Although HtrA2 is known to induce cell death, when upregulated, its underlying mechanism remains incompletely characterized. Experimental data supports the role of Omi/HtrA2 in neuronal cell death in ischemia reperfusion models, as well as myocardial cell death. Inhibition of Omi/HtrA2 has been shown to decrease the extent of the myocardial infarction and neuronal cell death. No data present in traumatic brain injury models..$^{59-61}$

AIF is a major player in the noncaspase-dependent apoptosis. Human AIF is synthesized as a precursor protein and converted to a mature AIF upon removal of the $\mathrm{N}$-terminal mitochondrial localization signal. Mature AIF is a flavoprotein with sequence similarity to bacterial nicotinamide adenine dinucleotide (NAD)-dependent oxidoreductases. By interacting directly with DNA and possibly displacing chromatin-associated proteins, AIF disrupts normal chromatin structure, leading to DNA condensation; it may also recruit downstream nucleases to induce caspase-independent 
partial chromatinolysis. In normal cells, AIF is confined to the mitochondria. On induction of apoptosis and upon increase in the permeability of the outer mitochondrial membrane, AIF translocates to the nucleus. The bcl-2 family proteins regulate the release of the AIF, where the antiapoptotic members of the bcl-2 family (bcl-2, bcl-XL) stabilize the mitochondrial membrane function as opposed to proapoptotic Bax and Bak, which increase mitochondrial permeability. Caspase inhibitors do not prevent the translocation of the AIF from the mitochondria to the nucleus. ATP depletion does not prevent AIF translocation. In cases of severe energetic cellular failure, AIF translocation does not lead to chromatin condensation, and the cell will have necrotic as opposed to apoptotic features. Addition of AIF to purified nuclei will induce partial chromatin condensation and DNA fragmentation. The translocation of AIF is an early event that takes place before the release of cytochrome c. Kinetic analysis confirms that the initial chromatin condensation to be associated with AIF release. Calpain 1 induces cleavage and release of AIF from isolated mitochondria. ${ }^{62}$ Calpain 1 was also found to be activated in neurons after ischemia and cleaves intramitochondrial AIF near its $N$ terminus. The truncation of AIF by calpain activity appeared to be essential for its translocation from mitochondria to the nucleus. ${ }^{63}$ Heat shock protein 70 (Hsp70) by antagonizing AIF provides antiapoptotic activity. Interestingly, Hsp70 also interacts with AIF to provide protection through the noncaspase pathway. ${ }^{64}$

Upon induction of apoptosis, several stages can be distinguished in the nuclear apoptosis, initially partial chromatin condensation, followed by marked chromatin condensation, and finally the formation of nuclear bodies. These changes seem to correlate with the release of AIF and cytochrome c, where the release of AIF precedes the release of cytochrome $c$. AIF has been implicated in the pathophysiology of focal ischemia, ${ }^{63,65}$ experimental traumatic brain injury, and spinal cord injury models ${ }^{66,67}$ The author was not able to detect AIF by means of immunohistochemistry in contused human brain tissue removed surgically after TBI.

Another protein that is released from the mitochondria exposed to apoptotic stimuli is endonuclease G. It is a mitochondrial nuclease that has been suggested to play a role in the mitochondrial DNA replication; $;{ }^{64}$ it is also implicated in DNA fragmentation during apoptosis. Endonuclease G is a mitochondrial specific nuclease that translocates to the nucleus during apoptosis; once released, endonuclease G cleaves chromatin DNA into nucleosomal fragments independent of caspases, endonuclease G similar to AIF is a caspaseindependent apoptotic pathway. ${ }^{68}$ Incubation of recombinant
tBid with isolated murine liver mitochondria induced the release of cytochrome $\mathrm{c}$ along with endonuclease G. In the same series of experiments, incubation with Bcl-2 prevented the release of cytochrome $\mathrm{c}$ and endonuclease $\mathrm{G} .{ }^{69}$

\section{Other regulatory mechanisms}

In normal unstressed cells, the level of p53 (tumor suppressor protein 53) is downregulated via the binding of proteins such as MDM2, COP1, PIRH2, or JNK. After stress, the p53 accumulates. Accumulation of p53 can leading to the activation of multiple transcription genes that can lead the cell to different outcomes including angiogenesis, growth arrest, DNA repair, and apoptosis. The mechanisms of p53-induced apoptosis are still uncertain, but the following mechanisms have been reported: upregulation of the CD95 (APO-1/Fas) receptor/ligand system that was documented in cancer cell lines exposed to chemotherapy and ionizing radiation..$^{70,71}$ Influence of 553 on the expression of the BCL-2 family members where $\mathrm{p} 53$ induces temperature-dependent decreases in the expression of the apoptosis-suppressing gene $b c l-2$ in the murine leukemia cell M1, while simultaneously stimulating increases in the expression of bax, a gene which encodes a dominant-inhibitor of the Bcl-2 protein, ${ }^{72,73}$ upregulation of DR5 and its ligand, ${ }^{74}$ the transcriptional induction of redoxrelated genes, the formation of reactive oxygen species, and the oxidative degradation of mitochondrial components, culminating in cell death. ${ }^{75}$

Another regulatory mechanism of apoptosis is tissue transglutaminase (tTG). tTG selectively accumulates in cells undergoing apoptosis both in vivo and in vitro. It was proposed that through hyperpolarization of the mitochondrial membrane, tTG might act as a "sensitizer" toward apoptotic stimuli specifically targeted to mitochondria. ${ }^{76}$ Further analysis identified tTG as BH3-containing protein that induced Bax oligomerization on mitochondria by catalyzing the polymerization of glutathione-S-transferase P1, thereby releasing its blocking effect on Bax. ${ }^{77}$ Other experiments had confirmed that injection of tTG into the cytosol has apoptotic activity, whereas intranuclear localization of tTG was antiapoptotic. ${ }^{78}$

Cyclin-dependent kinase 5 (CDK5) is a member of the small serine or threonine CDK family. CDK5R1 (p35)/ CDK5 may stimulate cell survival (inhibit cell apoptosis) via epidermal growth factor receptor family of receptor tyrosine kinases (ErbB), which eventually leads to downregulate the molecules involved in cell death of BCL-2 family. ${ }^{79}$ In addition, CDK5R1 (p35)/CDK5 may depress cell apoptosis via direct phosphorylation of c-Jun $N$-terminal kinase $3 .{ }^{80}$ It was also reported that CDK5R1 (p35)/CDK5 may repress 
nerve growth factor (NGF) and inhibits MEK1 activity, thus repressing $\mathrm{NGF} /$ Erk-dependent apoptosis. ${ }^{81}$

Nuclear factor kappa B (NF-B) is a transcription factor present in the nucleus of $\mathrm{B}$ cells that bound to the enhancer of the light chain of immunoglobulins ${ }^{82}$ and NF-B stimulates the expression of antiapoptotic genes including FLIP, cIAP, survivin, B-cell leukemia or lymphoma 2 (Bcl-2), and Bcl$\mathrm{XL} .{ }^{83}$ The inactive, latent form of NF-B is localized in the cytoplasm and is constituted by a heterotrimeric complex of p50, p65, and IB. ${ }^{84,85}$ Degradation of IB by sequential phosphorylation, ubiquitination, and proteasome-mediated proteolysis releases the $\mathrm{p} 50-\mathrm{p} 65$ heterodimer, which translocates to the nucleus and binds to specific consensus sequences within the promoter of NF-B target genes.

Apoptosis is regulated by many intracellular signaling pathways, including the c-Jun $\mathrm{N}$-terminal protein kinase (JNK) pathway. ${ }^{86} \mathrm{JNK}$ is a subfamily of the mitogenactivated protein kinase superfamily, and it was originally identified by its ability to specifically phosphorylate the transcription factor c-Jun on its $N$-terminal transactivation domain at 2 serine residues, Ser63 and Ser73 ${ }^{87}$ NF-B suppresses TNF-induced apoptosis by inhibiting caspases and preventing prolonged JNK activation. In the absence of NF-B activation, prolonged JNK activation contributes to TNF-induced apoptosis. However, prolonged JNK activation alone does not induce apoptosis but is able to promote TNFinduced apoptosis in the absence of NF-B activation; later, it was discovered that $\mathrm{JNK}$ activation regulates members of the Bcl-2 family (Bcl-2, Bcl-xL, Bim, BAD) ${ }^{88}$

\section{Detection of apoptosis}

Understanding the regulatory mechanisms of apoptosis and the time frame for apoptotic changes dictate the methods of detection and imaging. Electron microscopy has the ability to detect the morphological features of apoptosis, but because of the cumbersome nature and difficulty in the evaluation multiple samples, it became less popular. Terminal deoxynucleotidyl transferase dUTP nick end labeling (TUNEL) can identify DNA fragmentation, a characteristic of both apoptotic and necrotic cells. Gavrieli et a ${ }^{89}$ originally introduced TUNEL assay. Most of the medical research relies on TUNEL staining as indicator of apoptosis. Activated caspase- 3 detection has been proposed as an alternative, although some report activated caspase- 3 in necrosis (Figure 2). To discriminate apoptotic cells from necrotic cells, immunoreactivity of active caspases- 3 within a cell, in addition to TUNEL staining, can indicate that a cell is apoptotic vs necrotic and that is true if the apoptosis is a

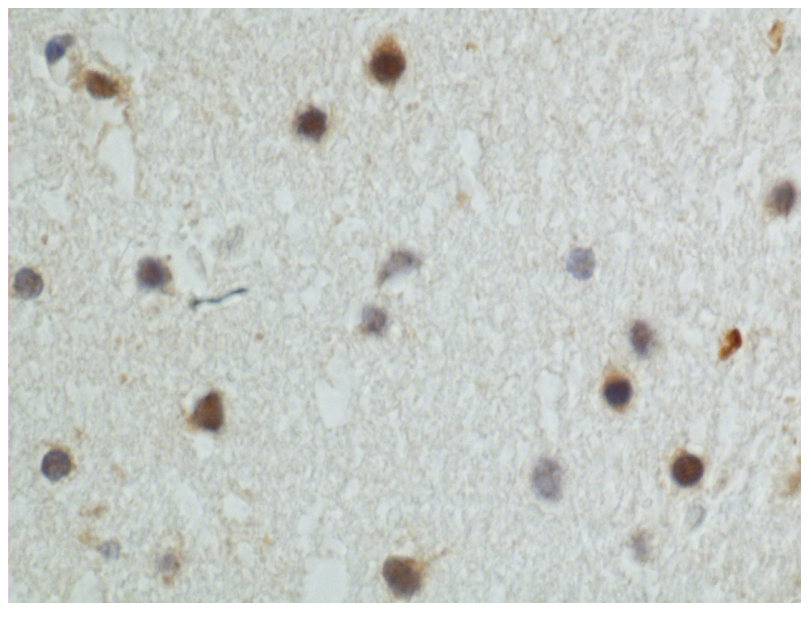

Figure 2 Immunohistochemical detection of activated caspase-3 (brown) in contused brain tissue removed after traumatic brain injury.

caspase-dependent process. This approach can be used in immunohistochemical detection of apoptosis.

Another method is the detection of single-stranded-DNA (ssDNA); large stretches of ssDNA occur in heat-denatured cells from mid to late stages of apoptosis. A specific antibody can detect the ssDNA.

In a study of the sensitivity and specificity of different staining methods to monitor apoptosis induced by oxidative stress in adherent cells, ssDNA detection was superior in detecting early apoptosis. ${ }^{90}$ Cytochrome c release is an essential step in the intrinsic pathway of apoptosis. During apoptosis, the outer mitochondrial membrane ruptures while both membranes fail during necrosis. The detection of released cytochrome $\mathrm{c}$ is specific for early to late stages of apoptosis if cells to be analyzed kept an intact inner membrane. Release of cytochrome c can be a marker of both apoptosis and necrosis.

\section{Imaging of apoptosis}

One of the earlier markers of apoptosis is externalization of phosphatidylserine (PS) residues from the inner to the outer leaflet of the cell membrane; ${ }^{91}$ the PS can present a signal for other cells including phagocytes for removal. Apoptosis imaging protocols are based upon the protein annexin A5 selective interaction with PS. ${ }^{92}$

Another PS-binding protein is the $\mathrm{C} 2$ domain of synaptotagmin I, by conjugating the $\mathrm{C} 2$ domain with superparamagnetic iron oxide (SPIO) particles, it makes a very effective T2-relaxing magnetic resonance imaging (MRI) contrast agent. Diffusion-weighted MRI (DWI) is an alternative MRI modality that can image apoptosis in response to radiation and chemotherapy without the need for a contrast agent; DWI 
generates image contrast by using the diffusion properties of water within tissues. ${ }^{93,94}$

Finally, an approach that relies on MRI spectroscopy is lipid proton magnetic resonance spectroscopy that is based on apoptosis-specific changes, including a selective increase in $\mathrm{CH}_{2}$ (methylene) relative to $\mathrm{CH}_{3}$ (methyl) mobile lipid proton signal intensities. ${ }^{95,96}$ Significant research is being conducted to identify molecular imaging agents for apoptosis including the detection of caspases such as activated caspase-3 in vivo. A novel promising marker is ML-10 (2-(5-fluoro-pentyl)-2-methyl-malonic acid), a member of the family of small-molecule detectors of apoptosis, that had shown selective accumulation in the cells with markers of caspase activation. ${ }^{97}$ This marker is undergoing phase 2 clinical trial for early detection of response of brain metastases to whole brain radiation therapy.

\section{Conclusion}

Apoptosis contributes to the pathophysiology of multiple disease processes including neurodegenerative diseases, stroke, and cancer. Understanding the regulatory mechanisms of apoptosis will assist in the development of imaging of programmed cell death, targeted drug discovery, and their implementation into clinical practice.

\section{Disclosure}

The author reports no conflict of interest in this work.

\section{References}

1. Graper L. Eine neue Anschauug uber physiologischeZellausschaltung. Arch Zeliforsch. 1914;12:373-394.

2. Kerr JFR. Shrinkage necrosis: a distinct mode of cellular death. JPathol. 1971;105(1):13-20.

3. Kerr JFR, Wyllie AH, Currie AR. Apoptosis: a basic biological phenomenon with wide ranging implications in tissue kinetics. Br J Cancer. 1972;26(4):239-257.

4. Bessis M. Studies on cell agony and death: an attempt at classification. In: de Reuck AVS, Knight J, editors. Cellular Injury. Ciba Foundation Symposium. London: J\&A Churchill; 1964:287-328.

5. Baehrecke EH. Autophagy: dual roles in life and death? Nat Rev Mol Cell Biol. 2005;6(6):505-510.

6. Castedo M, Perfettini JL, Roumier T, Andreau K, Medema R, Kroemer G. Cell death by mitotic catastrophe: a molecular definition. Oncogene. 2004;23(16):2825-2837.

7. EguchiY, Shimizu S, Tsujimoto Y. Intracellular ATP levels determine cell fate by apoptosis or necrosis. Cancer Res. 1997;57(10):1835-1840.

8. Leist MB, Castoldi AF, Kuhnle S, Nicotera P. Intracellular adenosine triphosphate(ATP) concentration: a switch in the decision between apoptosis and necrosis. J Exp Med. 1997;185(8):1481-1486.

9. Liu X, Zou H, Slaughter C, Wang X. DFF, a heterodimeric protein that functions downstream of caspase-3 to trigger DNA fragmentation during apoptosis. Cell. 1997;89(2):175-184.

10. Enari M, Sakahira H, Yokoyama H, Okawa K, Iwamatsu A, Nagata S. A caspase-activated DNase that degrades DNA during apoptosis, and its inhibitor ICAD. Nature. 1998;391(6662):43-50.
11. Urbano A, McCaffrey R, Foss F. Isolation and characterization of NUC70, a cytoplasmic hematopoietic apoptotic endonuclease. J Biol Chem. 1998;273(52):34820-34827.

12. Oliveri M, Daga A, Cantoni C, Lunardi C, Millo R, Puccetti A. DNase 1 mediates intranucleosomal DNA degradation in human cells undergoing drug induced apoptosis. Eur J Immunol. 2001;31(3):743-751.

13. Krueger A, Baumann S, Krammer PH, Kirchhoff S. FLICE-inhibitory proteins: regulators of death receptor-mediated apoptosis. Mol Cell Biol. 2001;21(24):8247-8254.

14. Micheau O. Cellular FLICE-inhibitory protein: an attractive therapeutic target? Expert Opin Ther Targets. 2003;7(4):559-573.

15. Petak I, Vernes R, Szucs KS, et al. A caspase-8-independent component in TRAIL/Apo-2L-induced cell death in human rhabdomyosarcoma cells. Cell Death Differ. 2003;10(6):729-739.

16. Miura Y, Koyanagi Y, Mizusawa H. TNF-related apoptosis-inducing ligand (TRAIL) induces neuronal apoptosis in HIV-encephalopathy. J Med Dent Sci. 2003;50(1):17-25.

17. Marsters SA, Pitti RM, Donahue CJ, Ruppert S, Bauer KD, Ashkenazi A. Activation of apoptosis by Apo-2 ligand is independent of FADD but blocked by CrmA. Curr Biol. 1996;6(6):750-752.

18. Wang L, Du F, Wang X. TNF-alpha induces two distinct caspase-8 activation pathways. Cell. 2008;133(4):693-703.

19. Scorrano L, Korsmyer SJ. Mechanism of cytochrome c release by proapoptotic BCL-2 family members. Biochem Biophys Res Commun. 2003;304:437-444.

20. Barnhart BC, Alappat EC, Peter ME. The CD95 type I/type II model. Sem Immunol. 2003; 15(3):185-193.

21. Zhao Y, Li S, Childs EE, Kuharsky DK, Yin XM. Activation of pro death BCL-2 family proteins and mitochondria apoptosis pathway in TNFalpha induced liver injury. J Biol Chem. 2001;276(29):27432-27440.

22. Riedl SJ, Renatus M, Schwarzenbacher R, et al. Structural basis for the inhibition of caspase-3 by XIAP. Cell. 2001;104(5):791-800.

23. Bredesen DE, Mehlen P, Rabizadeh S. Apoptosis and dependence receptors: a molecular basis for cellular addiction. Physiol Rev. 2004; 84(2):411-430.

24. Levi-Montalcini R. The nerve growth factor: its mode of action on sensory and sympathetic nerve cells. Harvey Lect. 1966;60:217-259.

25. Barrett GL, Bartlett PF. The p 75 nerve growth factor receptor mediates survival or death depending on the stage of sensory neuron development. Proc Natl Acad Sci U S A. 1994;91(14):6501-6505.

26. Casaccia-Bonnefil P, Carter BD, Dobrowsky RT, Chao MV. Death of oligodendrocytes mediated by the interaction of nerve growth factor with its receptor p75. Nature. 1996;383(6602):716-719.

27. Chi S, Kitanaka C, Noguchi K, et al. Oncogenic Ras triggers cell suicide through the activation of a caspase-independent cell death program in human cancer cells. Oncogene. 1999;18(13):2281-2290.

28. Forcet C, Ye X, Granger L, et al. The dependence receptor DCC (deleted in colorectal cancer) defines an alternative mechanism for caspase activation. Proc Natl Acad Sci U S A. 2001;98(6):3416-3421.

29. Liu J, Yao F, Wu R, et al. Mediation of the DCC apoptotic signal by DIP13 alpha. J Biol Chem. 2002;277(29):26281-26285.

30. Llambi F, Causeret F, Bloch-Gallego E, Mehlen P. Netrin-1 acts as a survival factor via its receptors UNC5H and DCC. EMBO J. 2001; 20(11):2715-2722.

31. Mulligan LM, Kwok JB, Healey CS, et al. Germ-line mutations of the RET proto-oncogene in multiple endocrine neoplasia type 2A. Nature. 1993;363(6428):458-460.

32. Singhvi R, Kumar A, Lopez GP, Stephanopoulos GN, Wang DI, Whitesides GM. Engineering cell shape and function. Science. 1994; 264:696-698.

33. Frisch SM, Ruoslahti E. Integrins and anoikis. Curr Opin Cell Biol. 1997;(5):701-706.

34. Miyazaki T, Shen M, Fujikura D, et al. Functional role of death-associated protein 3 (DAP3) in anoikis. J Biol Chem. 2004;279(43):44667-44672.

35. Yang J, Liu X, Bhalla K, et al. Prevention of apoptosis by Bcl-2: release of cytochrome c from mitochondria blocked. Science. 1997;275(5303): 1129-1132. 
36. Vander Heiden MG, Chandel NS, Williamson EK, Schumacker PT, Thompson CB. Bcl-xL regulates the membrane potential and volume homeostasis of mitochondria. Cell. 1997;91(5):627-637.

37. Funk RH, Nagel F, Wonka F, Krinke HE, Golfert F, Hofer A. Effects of heat shock on the functional morphology of cell organelles observed by video-enhanced microscopy. Anat Rec. 1999;255(4):458-464.

38. Dang CV, Semenza GL. Oncogenic alterations of metabolism. Trends Biochem Sci. 1999;24:68-72.

39. Vander Heiden MG, Chandel NS, Schumacker PT, Thompson CB. Bcl-xL prevents cell death following growth factor withdrawal by facilitating mitochondrial ATP/ADP exchange. Mol Cell. 1999;3(2):159-167.

40. Jurgensmeier JM, Xie Z, Deveraux Q, Ellerby L, Bredesen D, Reed JC. Bax directly induces release of cytochrome $\mathrm{c}$ from isolated mitochondria. Proc Natl Acad Sci U S A. 1998;95(9):4997-5002.

41. Gross A, Yin XM, Wang K, Caspase Cleaved BID targets mitochondria and is required for cytochrome $\mathrm{c}$ release, while BCL-XL prevents this release but not tumor necrosis factor-R1/Fas death. $J$ Biol Chem. 1999;274(2): 1156-1163.

42. Madesh M, Antonsson B, Srinivasula SM, Hajnoczky G. Rapid Kinetics of tBID-induced cytochrome $\mathrm{c}$ and Smac/DIABLO Release and Mitochondrial Depolarization. J Biol Chem. 2002;277(7):5651-5659.

43. Li H, Zhu H, Xu CJ, Yan J. Cleavage of BID by caspase-8 mediates the mitochondrial damage in the apoptosis. Cell. 1998;94(4):491-501.

44. Datta SR, Dudek H, Tao X. Akt phosphorylation of BAD couples survival signals to the cell - intrinsic death machinery. Cell. 1997;91(2): 231-241.

45. Hu Y, Benedict MA, Wu D, Inohara N, Núñez G. Bcl-XL interacts with Apaf-1 and inhibits Apaf-1-dependent caspase-9 activation. Proc Natl Acad Sci U S A. 1998;95(8):4386-4391.

46. Huang DC, Adams JM, Cory S. The conserved N-terminal BH4 domain of Bcl-2 homologues is essential for inhibition of apoptosis and interaction with CED-4. EMBO J. 1998;17(4):1029-1039.

47. Pan G, O'Rourke K, Dixit VM. Caspase-9, Bcl-XL, and Apaf-1 form a ternary complex. J Biol Chem. 1998;273(10):5841-5845.

48. Zou H, Li Y, Liu X, Wang X. An APAF-1.cytochrome c multimetric complex is a functional apoptosome that activates procaspase-9. J Biol Chem. 1999;274(17):11549-11556.

49. Duckett CS, Li F, Tomaselli KJ, Thompson CB, Armstrong RC. Human IAP like protein regulates programmed cell death downstream of BCL-XL and cytochrome c. Mol Cell Biol. 1998;18(1):608-615.

50. Ambrosini G, Adida C, Altieri DC. A novel antiapoptotic gene survivin, expressed in cancer and lymphoma. Nat Med. 1997;3(8):917-921.

51. Deveraux QL, Takahashi R, Salvesen GS, Reed JC. X-linked IAP is a direct inhibitor of cell death proteases. Nature. 1997;388(6639):300-304.

52. Xu DG, Crocker JP, Robenson GS. Elevation of neuronal expression of NAIP reduces ischemic damage the rat hippocampus. Nat Med. 1997;3(9):997-1004.

53. Basova LV, Kurnikov IV, Wang L, et al. Cardiolipin switch in mitochondria: shutting off the reduction of cytochrome $\mathrm{c}$ and turning on the peroxidase activity. Biochemistry. 2007;46(11):3423-3434.

54. Wu G, Chai J, Suber TL, Wu JW, Du C, Wang X. Structural basis for IAP recognition by Smac/Diablo. Nature. 2000;408:1008-1012.

55. Bratton SB, Walker G, Srinvasula SV, Butterworth M, Alnemiri ES, Cohen GM. Recruitment, activation, and retention of caspase- 9 and -3 by apaf-1 apoptosome and associated XIAP complexes. EMBO J. 2001;20(5):998-1009.

56. Yang Y, Fang S, Jensen JP, Weissman AM, Ashwell JD. Ubiquitin protein ligase activity of IAPs and their degradation in proteosomes in response to apoptotic stimuli. Science. 2000;288(5467):874-877.

57. Suzuki Y, Nakabayashi Y, Takahashi R. Ubiquitin protein ligase activity on X-linked inhibitor of apoptosis protein promotes proteasomal degradation of caspase-3 and enhances its antiapoptotic effect in Fas induced cell death. Proc Natl Acad Sci. 2001;98:8662-8667.

58. Scarabelli TM, Stephanou A, Pasini E, et al. Minocycline inhibits caspase activation and reactivation, increases the ratio of XIAP to smac/ DIABLO, and reduces the mitochondrial leakage of cytochrome $\mathrm{C}$ and smac/DIABLO. J Am Coll Cardiol. 2004;43(5):865-874.
59. Bhuiyan MS, Fukunaga K. Inhibition of HtrA2/Omi ameliorates heart dysfunction following ischemia/reperfusion injury in rat heart in vivo. Eur J Pharmacol. 2007;557(2-3):168-177.

60. Su D, Su Z, Wang J, Yang S, Ma J. UCF-101, a novel Omi/HtrA2 inhibitor, protects against cerebral ischemia/reperfusion injury in rats. Anat Rec (Hoboken). 2009;292(6):854-861.

61. Bhuiyan MS, Fukunaga K. Mitochondrial serine protease HtrA2/Omi as a potential therapeutic target. Curr Drug Targets. 2009;10(4):372-383.

62. Polster BM, Basañez G, Etxebarria A, Hardwick JM, Nicholls DG. Calpain I induces cleavage and release of apoptosis-inducing factor from isolated mitochondria. J Biol Chem. 2005;280(8):6447-6454.

63. Cao G, Xing J, Xiao X, et al. Critical role of calpain I in mitochondrial release of apoptosis-inducing factor in ischemic neuronal injury. J Neurosci. 2007;27(35):9278-9293.

64. Ravagnan L, Gurbuxani S, Susin S, Maisse C, Kroemer G. Heatshock protein 70 antagonizes apoptosis-inducing factor. Nat Cell Biol. 2001;(9):839-843.

65. Pallast $\mathrm{S}$, Arai $\mathrm{K}$, Pekcec $\mathrm{A}$, et al. Increased nuclear apoptosis-inducing factor after transient focal ischemia: a 12/15-lipoxygenase-dependent organelle damage pathway. J Cereb Blood Flow Metab. 2010;30(6):1157-1167.

66. Slemmer JE, Zhu C, Landshamer S, et al. Causal role of apoptosisinducing factor for neuronal cell death following traumatic brain injury. Am J Pathol. 2008;173(6):1795-1805.

67. Schwab JM, Frei E, Klusman I, Schnell L, Schwab ME, Schluesener HJ. AIF-1 expression defines a proliferating and alert microglial $/ \mathrm{mac}-$ rophage phenotype following spinal cord injury in rats. J Neuroimmunol. 2001;119(2):214-222.

68. Li LY, Luo X, Wang X. Endonuclease G is an apoptotic DNase when released from mitochondria. Nature. 2001;412(6842):95-99.

69. van Loo G, Schotte P, van Gurp M, et al. Endonuclease G: a mitochondrial protein released in apoptosis and involved in caspase-independent DNA degradation. Cell Death Differ. 2001;8(12):1136-1142.

70. Muller M, Wilder S, Bannasch D, et al. p53 activates the CD95 (APO-1/ Fas) gene in response to DNA damage by anticancer drugs. J Exp Med. 1998;188(11):2033-2045.

71. Sheard MA, Vojtesek B, Janakova L, Kovarik J, Zaloudik J. Upregulation of Fas (CD95) in human p53 wild-type cancer cells treated with ionizing radiation. Int J Cancer. 1997;73:757-762.

72. Miyashita T, Krajewski S, Krajewska M. Tumor suppressor p53 is a regulator of bcl-2 and bax gene expression in vitro and in vivo. Oncogene. 1994;9(6):1799-1805.

73. Zhan Q, Fan S, Bae I, et al. Induction of bax by genotoxic stress in human cells correlates with normal p53 status and apoptosis. Oncogene. 1994;9(12):3743-3751.

74. Wu GS, Burns TF, McDonald ERI, et al. KILLER/DR5 is a DNA damage-inducible p53-regulated death receptor gene. Nat Genet. 1997; 17(2):141-143.

75. Polyak K, Xia Y, Zweier JL, Kinzler KW, Vogelstein B. A model for p53-induced apoptosis. Nature. 1997;389(6648):300-305.

76. Piacentini M, Farrace MG, Piredda L, et al. Transglutaminase overexpression sensitizes neuronal cell lines to apoptosis by increasing mitochondrial membrane potential and cellular oxidative stress. J Neurochem. 2002;81(5):1061-1072.

77. Oliverio S, Amendola A, Rodolfo C, Spinedi A, Piacentini M. Inhibition of "tissue" transglutaminase increases cell survival by preventing apoptosis. J Biol Chem. 1999;274(48):34123-34128.

78. Milakovic T, Tucholski J, McCoy E, Johnson GV. Intracellular localization and activity state of tissue transglutaminase differentially impacts cell death. J Biol Chem. 2004;279(10):8715-8722.

79. Datta SR, Brunet A, Greenberg ME. Cellular survival: a play in three Akts. Genes Dev. 1999;13(22):2905-2927.

80. Li BS, Zhang L, Takahashi S, et al. Cyclin-dependent kinase 5 prevents neuronal apoptosis by negative regulation of c-Jun N-terminal kinase 3 . EMBO J. 2002;21(3):324-333.

81. Zheng YL, Li BS, Kanungo J, et al. Cdk5 Modulation of mitogenactivated protein kinase signaling regulates neuronal survival. Mol Biol Cell. 2007;18(2):404-413. 
82. Ghosh S, Karin M. Missing pieces in the NF-kappaB puzzle. Cell. 2002; Suppl 109:S81-S96.

83. Turco MC, Romano MF, Petrella A, Bisogni R, Tassone P, Venuta S. NF-kappaB/Rel-mediated regulation of apoptosis in hematologic malignancies and normal hematopoietic progenitors. Leukemia. 2004; 18(1):11-17.

84. Hayden MS, Ghosh S. Signaling to NF-kappaB. Genes Dev. 2004; 18(18):2195-2224.

85. Karin M, Cao Y, Greten FR, Li ZW. NF-kappaB in cancer: from innocent bystander to major culprit. Nat Rev Cancer. 2002;2(4):301-310.

86. Shaulian E, Karin M. AP-1 as a regulator of cell life and death. Nat Cell Biol. 2002;4(5):E131-E136.

87. Hibi M, Lin A, Smeal T, Minden A, Karin M. Identification of an oncoprotein- and UV-responsive protein kinase that binds and potentiates the c-Jun activation domain. Genes Dev. 1993;7(11):2135-2148.

88. Yu C, Minemoto Y, Zhang J, et al. JNK suppresses apoptosis via phosphorylation of the proapoptotic Bcl-2 family protein BAD. Molecular Cell. 2004;13(3):329-340.

89. Gavrieli Y, Sherman Y, Ben-Sasson S. Identification of programmed cell death in situ via specific labeling of nuclear DNA fragmentation. J Cell Biol. 1992;119(3):493-501.

90. Zhao J, Schmid-Kotsas A, Gross HJ, Gruenert A, Bachem MG. Sensitivity and specificity of different staining methods to monitor apoptosis induced by oxidative stress in adherent cells. Chin Med J (Engl). 2003;116(12):1923-1929.
91. Fadok VA, Voelker DR, Campbell PA, Cohen JJ, Bratton DL, Henson PM. Exposure of phosphatidylserine on the surface of apoptotic lymphocytes triggers specific recognition and removal by macrophages. J Immun. 1992;148(7):2207-2216.

92. Fadok VA, Bratton DL, Frasch SC, Warner ML, Henson PM. The role of phosphatidylserine in recognition of apoptotic cells by phagocytes. Cell Death Differ. 1998;5(7):551-562.

93. Charles-Edwards EM, deSouza NM. Diffusion-weighted magnetic resonance imaging and its application to cancer. Cancer Imaging. 2006; 6:135-143.

94. Lidar Z, Mardor Y, Jonas T, et al. Convection-enhanced delivery of paclitaxel for the treatment of recurrent malignant glioma: a phase I/II clinical study. J Neurosurg. 2004;100(3):472-479.

95. Blankenberg FG, Storrs RW, Naumovski L, Goralski T, Spielman D. Detection of apoptotic cell death by proton nuclear magnetic resonance spectroscopy. Blood. 1996;87(5):1951-1956.

96. Engelmann J, Henke J, Willker W, et al. Early stage monitoring of miltefosine induced apoptosis in KB cells by multinuclear NMR spectroscopy. Anticancer Res. 1996;16(3B):1429-1439.

97. Cohen A, Shirvan A, Levin G, Grimberg H, Reshef A, Ziv I. From the GLA domain to a novel small molecule detector of apoptosis. Cell Res. 2009;19(5):625-637.
Cell Health and Cytoskeleton

\section{Publish your work in this journal}

Cell Health and Cytoskeleton is an international, peer-reviewed open access journal focusing on all aspects of cell structure and function contributing to normal physiology and cell health and exploring the pathogenesis of cell dysfunction leading to adverse conditions and disease in the organism. The journal welcomes papers covering original research,

\section{Dovepress}

basic science, reviews and evaluations, guidelines, expert opinion and commentary, case reports and extended reports. The manuscript management system is completely online and includes a very quick and fair peerreview system, which is all easy to use. Visit http://www.dovepress.com/ testimonials.php to read real quotes from published authors. 